\title{
Optimization of nonlinear optical properties of ZnO micro and nanocrystals for biophotonics
}

\author{
Ben E. Urban, ${ }^{1}$ Jie Lin, ${ }^{1}$ Os Kumar, ${ }^{2}$ Kasilingam Senthilkumar, ${ }^{2}$ Yasuhisa Fujita, ${ }^{2}$ and \\ Arup Neogi ${ }^{1 \text { ** }}$ \\ ${ }^{1}$ Department of Physics, University of North Texas, 1155 Union Circle, Denton, TX 76203, USA \\ ${ }^{2}$ Department of Electronic and Control System Engineering, Shimane University, 1060 Nishikawatsu, Matsue, \\ 6908504, Japan \\ *arup@unt.edu
}

\begin{abstract}
The defect and impurity states in $\mathrm{ZnO}$ nanocrystals synthesized using the plasma arc technique can be modified to optimize the nonlinear optical properties for optoelectronic and biophotonic applications. Highly efficient second harmonic signals over a wide range of near-infrared wavelengths, spanning from $735 \mathrm{~nm}-980 \mathrm{~nm}$, has been observed and can be used in biological imaging. The use of further high energy excitation ranging from $700 \mathrm{~nm}-755 \mathrm{~nm}$ leads to two-photon absorption and yields broadband two photon emission extending from the $370 \mathrm{~nm}-450 \mathrm{~nm}$ wavelength regime which can be useful for therapeutic applications.
\end{abstract}

(C)2011 Optical Society of America

OCIS codes: (160.4330) Nonlinear optical materials; (180.4315) Nonlinear microscopy.

\section{References and links}

1. S. John, S. Marpu, J. Li, M. Omary, Z. Hu, Y. Fujita, and A. Neogi, "Hybrid zinc oxide nanoparticles for biophotonics,” J. Nanosci. Nanotechnol. 10(3), 1707-1712 (2010).

2. A. V. Kachynski, A. N. Kuzmin, M. Nyk, I. Roy, and P. N. Prasad, "Zinc oxide nanocrystals for nonresonant nonlinear optical microscopy," J. Phys. Chem. C 112(29), 10721-10724 (2008).

3. E. S. P. Leong, S. F. Yu, and S. P. Lau, "Directional edge-emitting UV random laser diodes," Appl. Phys. Lett. 89(22), 221109 (2006).

4. U. Özgür, Y. I. Alivov, C. Liu, A. Teke, M. A. Reshchikov, S. Dogan, V. Avrutin, S. J. Cho, and H. Morkoc, “A comprehensive review of ZnO materials and devices," J. Appl. Phys. 98(4), 041301 (2005).

5. J. V. Foreman, H. O. Everitt, J. Yang, T. McNicholas, and J. Liu, "Effects of reabsorption and spatial trap distributions on the radiative quantum efficiencies of ZnO,” Phys. Rev. B 81(11), 115318 (2010).

6. Y. L. Wu, S. Fu, A. I. Y. Tok, X. T. Zeng, C. S. Lim, L. C. Kwek, and F. C. Y. Boey, "A dual-colored biomarker made of doped ZnO nanocrystals," Nanotechnology 19(34), 345605 (2008).

7. T. Voss, I. Kudyk, L. Wischmeier, and J. Gutowski, "Nonlinear optics with ZnO nanowires," Phys. Status Solidi B 246(2), 311-314 (2009).

8. P. Pantazis, J. Maloney, D. Wu, and S. E. Fraser, "Second harmonic generating (SHG) nanoprobes for in vivo imaging," Proc. Natl. Acad. Sci. U.S.A. 107(33), 14535-14540 (2010).

9. C. Zhang, F. Zhang, T. Xia, N. Kumar, J. I. Hahm, J. Liu, Z. L. Wang, and J. Xu, "Low-threshold two-photon pumped ZnO nanowire lasers," Opt. Express 17(10), 7893-7900 (2009).

10. K. Senthilkumar, M. Tokunaga, H. Okamoto, O. Senthilkumar, J. Lin, B. Urban, A. Neogi, and Y. Fujita, "Multiphonon scattering and non-radiative decay in ZnO nanoparticles," Phys. Status Solidi C 7(6), 1586-1588 (2010).

11. K. Senthilkumar, M. Tokunaga, H. Okamoto, O. Senthilkumar, and Y. Fujita, "Hydrogen related defect complexes in ZnO nanoparticles," Appl. Phys. Lett. 97(9), 091907 (2010).

12. H. Zeng, G. Duan, Y. Li, S. Yang, X. Xu, and W. Cai, "Blue luminescence of $\mathrm{ZnO}$ nanoparticles based on nonequillibrium processes: Defect origins and emission controls," Adv. Funct. Mater. 20(4), 561-572 (2010).

13. M. D. McCluskey, S. J. Jokela, and W. M. Hlaing Oo, "Hydrogen donors in ZnO," Materials Research Society Symposium Proceedings (2005), Vol. 864, pp. E10.4.1-E10.4.10.

14. B. K. Meyer, H. Alves, D. M. Hofmann, W. Kriegseis, D. Forster, F. Bertram, J. Christen, A. Hoffmann, M. Straßburg, M. Dworzak, U. Haboeck, and A. V. Rodina, "Bound exciton and donor-acceptor pair recombinations in ZnO,” Phys. Status Solidi, B Basic Res. 241(2), 231-260 (2004).

15. T. M. Borseth, B. G. Svensson, A. Y. Kuznetsov, P. Klason, Q. X. Zhao, and M. Willander, "Identification of oxygen and zinc vacancy optical signals in ZnO," Appl. Phys. Lett. 89(26), 262112 (2006). 
16. A. Zubiaga, J. A. García, F. Plazaola, F. Tuomisto, K. Saarinen, J. Zuñiga Pérez, and V. Muñoz-Sanjosé, "Correlation between Zn vacancies and photoluminescence emission in ZnO films," J. Appl. Phys. 99(5), 053516 (2006).

17. M. G. Wardle, J. P. Goss, and P. R. Briddon, "Theory of Fe, Co, Ni, Cu, and their complexes with hydrogen in ZnO,” Phys. Rev. B 72(15), 155108 (2005).

18. K. Ip, M. E. Overberg, Y. W. Heo, D. P. Norton, S. J. Pearton, C. E. Stutz, S. O. Kucheyev, C. Jagadish, J. S. Williams, B. Luo, F. Ren, D. C. Look, and J. M. Zavada, "Hydrogen incorporation, diffusivity and evolution in bulk ZnO," Solid-State Electron. 47(12), 2255-2259 (2003).

19. J. Bang and K. J. Chang, "Atomic structure and diffusion of hydrogen in ZnO," J. Korean Phys. Soc. 55(1), 98$102(2009)$.

20. F. Oba, A. Togo, I. Tanaka, J. Paier, and G. Kresse, "Defect energetics in ZnO: a hybrid Hartree-Fock density functional study," Phys. Rev. B 77(24), 245202 (2008).

21. J. Yang, X. Liu, L. Yang, Y. Wang, Y. Zhang, J. Lang, M. Gao, and B. Feng, "Effects of annealing temperature on the structure and optical properties of ZnO nanoparticles," J. Alloy. Comp. 477(1-2), 632-635 (2009).

22. P. Singh, A. Kumar, A. Kaushal, D. Kaur, A. Pandey, and R. N. Goyal, "In situ high temperature XRD studies of $\mathrm{ZnO}$ nanopowder prepared via cost effective ultrasonic mist chemical vapour deposition," Bull. Mater. Sci. 31(3), 573-577 (2008)

\section{Introduction}

Owing to the high exciton binding energy $(\sim 60 \mathrm{meV})$ and direct bandgap, ZnO exhibits bright photoluminescence at room temperature. $\mathrm{ZnO}$ thin films and nanocrystals have potential application in light emitting diodes, laser diodes, detectors, white light sources, and biological markers [1-4]. The low toxicity of $\mathrm{ZnO}$ nanocrystals and the tunable properties of its photoluminescence in the UV and visible wavelength range make it viable for in vivo imaging $[2,5,6]$. However, due to the wide bandgap of $\mathrm{ZnO}(\sim 3.34 \mathrm{eV})$, single photon excitation and subsequent PL emission in the UV range make $\mathrm{ZnO}$ less efficient for use as markers for imaging of biological systems. This has led to the increased interest in the study of nonlinear optical properties of $\mathrm{ZnO}$ which require optical excitation, or generation for harmonics, in the near-infrared wavelength regime [2,5,7-9].

However, the nonlinear optical properties, including second-harmonic generation (SHG) and the two-photon emission (TPE) process in $\mathrm{ZnO}$ nanomaterials, such as nanoparticles, nanowires and nanotubes, are not well understood. In most reports, $\mathrm{ZnO}$ materials are reported to exhibit either SHG or TPE depending on the surface orientation or nature of defect states within the nanostructures [4,5,10-16]. As the linear and nonlinear absorption depends on the impurities and crystal defects at the surface and inside the crystal structure, a systematic control of the synthesis process can provide a means to tailor the optical properties of the system. The induction of oxygen related vacancies in $\mathrm{ZnO}$ has been reported to lead to green emission $[4,5,12]$ only when electrons are excited into the conduction band, providing additional states for the two-photon process.

In this article, we investigate the defects in $\mathrm{ZnO}$ created during its synthesis and its affect on the second $\left[\chi^{(2)}\right]$ and third-order $\left[\chi^{(3)}\right]$ nonlinear processes. We present the characteristics of the tunable and narrow spectral width of the second-harmonic generated signal, which is suitable for biological tracking and imaging. The TPE, which can be used for localized heating of the intracellular regions, is also presented. Our crystals are susceptible to nonlinear processes in a continuous range from visible to infrared.

\section{Experimental}

$\mathrm{ZnO}$ nanocrystals, in powder form, were created at different conditions using an arc plasma method [10]. In this paper, we present the results of optical nonlinearity in $\mathrm{ZnO}$ nanocrystals synthesized under four different conditions. One sample was made at atmospheric pressure in an air ambient with an arc current of 90 A (sample 1). A second sample was made at a pressure of 305 Torr with an arc current of 90 A (sample 3). Sample 1 and sample 3 were then annealed in atmosphere at $1000^{\circ} \mathrm{C}$ for 1 hour (sample 2 and sample 4 , respectively). The structural properties, including the interface or surface quality, were studied using electron microscopy. The particle size was analyzed using high resolution scanning electron 
microscopy and dynamic light scattering measurements. The internal strain and the presence of impurities were studied using Raman spectroscopy and X-ray diffraction (XRD). The nonlinear optical processes in the $\mathrm{ZnO}$ samples were studied using a Ti:Sapphire laser with a pulse width of 80 fs and a Hamamatsu streak camera with 15 ps resolution to measure the time-integrated second harmonic generation (SHG) and two photon time resolve photo luminescence (TRPL). A description of the crystal shapes and size distributions are given in Figs. 1, 2 and 3. The optical setup for measuring the TPE and SHG processes is shown in Fig. 4.

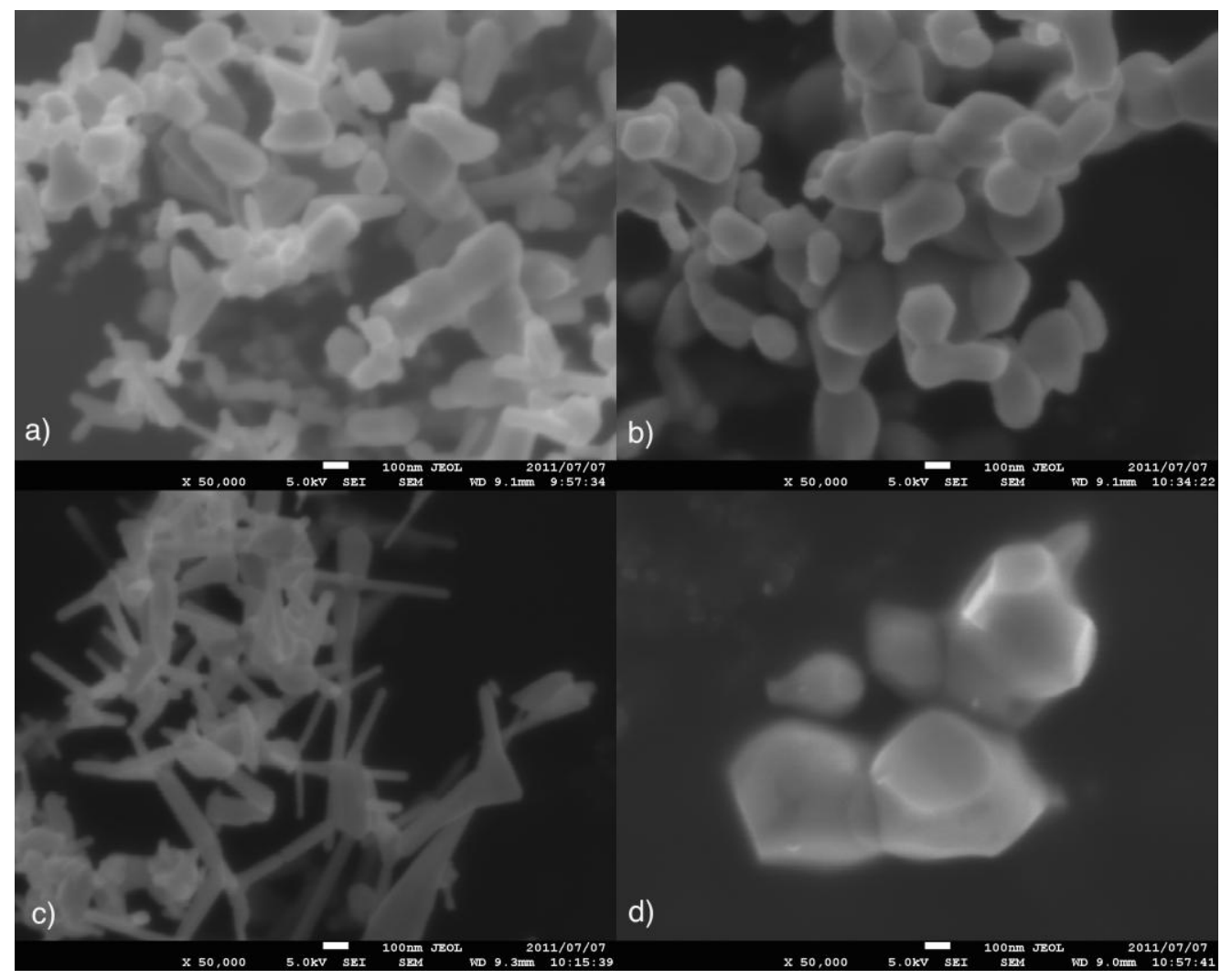

Fig. 1. SEM pictures of samples 1(a), 2(b), 3(c) and 4(d). After annealing at high temperatures the shapes of the crystals change from nanorods, tetrapods and nanoparticles to that of semispherical particles. The white scale in the SEM pictures is $100 \mathrm{~nm}$. 

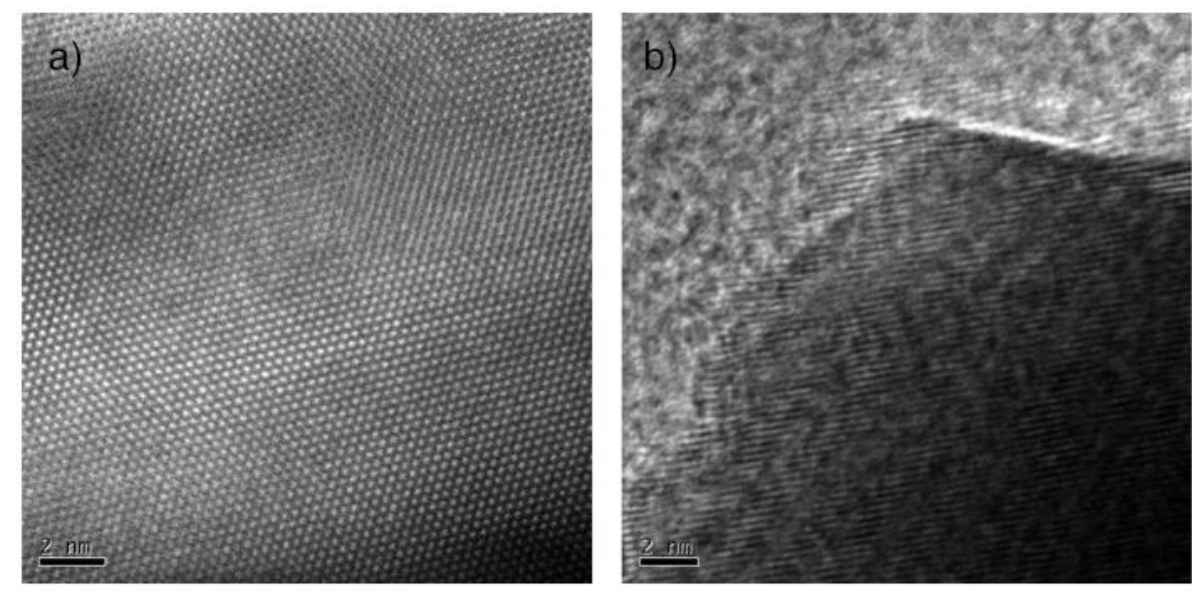

Fig. 2. (a) shows the TEM image at the interface of a annealed particle, whereas (b) shows the high resolution TEM surface image of the same $\mathrm{ZnO}$ particle. The scale bar is $2 \mathrm{~nm}$ for both TEM figures. One can see structural defects at the surface.
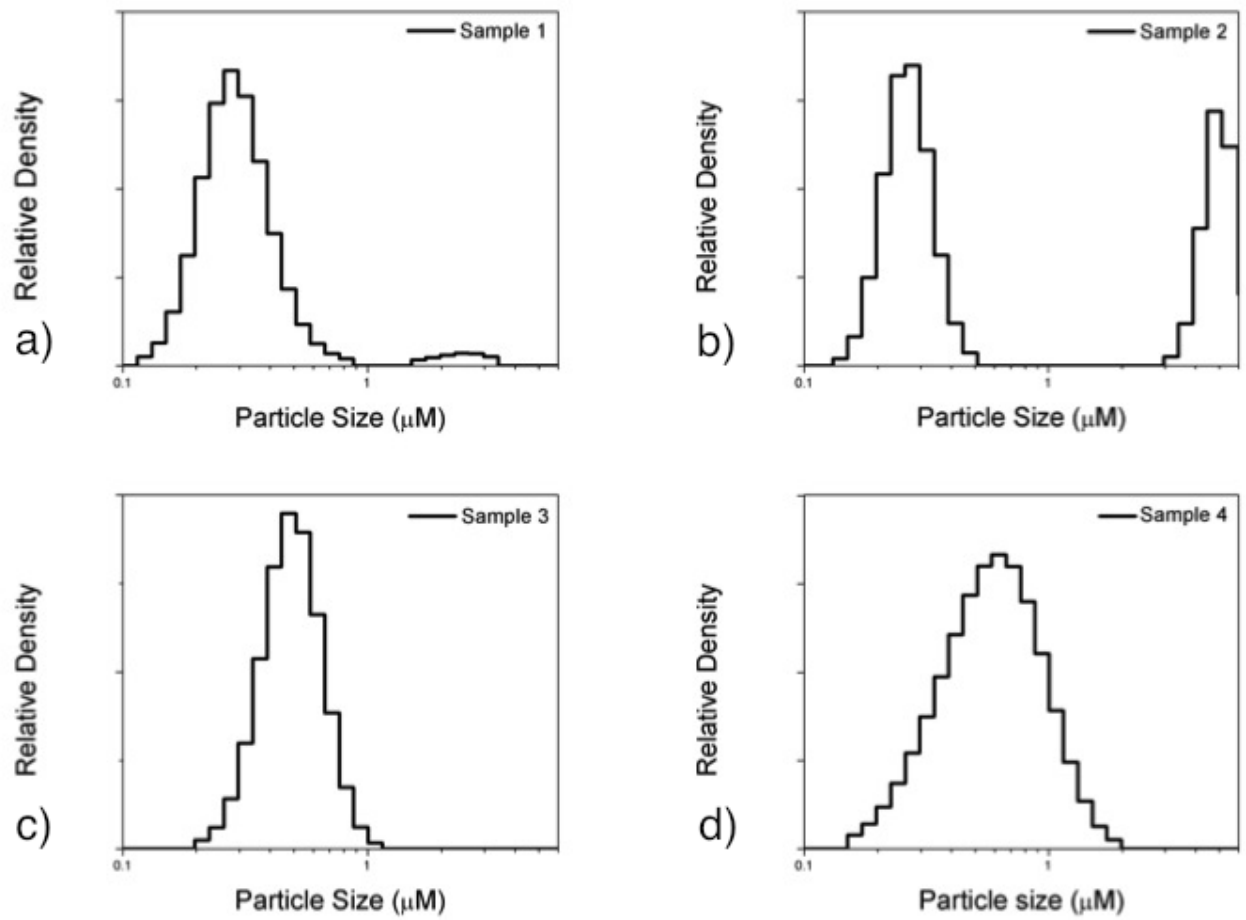

Fig. 3. The size distribution of samples 1 (a), 2 (b), 3 (c) and 4 (d) measured by dynamic light scattering. The $\mathrm{ZnO}$ nanocrystals of dimensions less than $20 \mathrm{~nm}$ were homogenized into a colloidal solution by centrifugation, and the particle size was reconfirmed by the SEM images. 


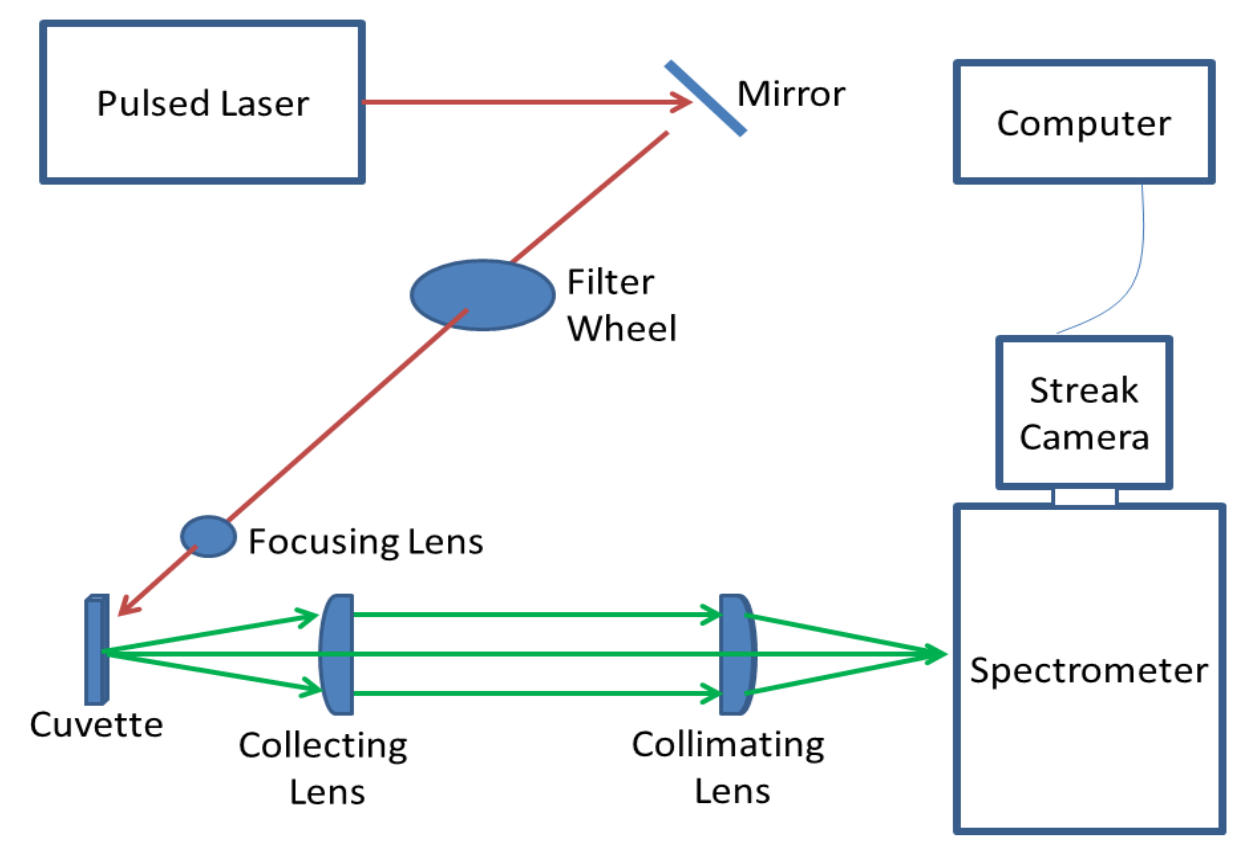

Fig. 4. A schematic of the experimental setup used to measure the TPE and SHG of all samples. A special holder for the cuvette was made to allow it to return to the same position after removing it to change samples. Samples were packed into the cuvette to get the same densities. However, both annealed sampled proved to be less dense after taking volume and weight measurements of the samples in the cuvette.

\section{Results and Discussion}

The presence of impurities studied by Raman and XRD analysis is shown in Figs. 5 and 6. According to Raman and XRD data, hydrogen is significantly present only in the as prepared atmospheric sample (sample 1). All common Raman peaks associated with crystalline $\mathrm{ZnO}$ were present [4], however excess XRD peaks indicating $\mathrm{Zn}(\mathrm{OH})_{2}$ complex were observed only in sample 1. In the Raman spectrum, a large peak is observed at $1057 \mathrm{~cm}^{-1}$ and several other peaks from $3200-4000 \mathrm{~cm}^{-1}$ for sample 1, indicating the presence of $\mathrm{C}-\mathrm{O}, \mathrm{O}-\mathrm{H}$ and $\mathrm{Zn}(\mathrm{OH})_{2}$ complex in the sample [11,17] (Fig. 6). Since the bonding energy of $\mathrm{Zn}(\mathrm{OH})_{2}, \mathrm{C}-\mathrm{O}$ and $\mathrm{O}-\mathrm{H}$ are weak, these defects are easily removed in the annealing process $[18,19]$. Because of the fabrication conditions, sample 1 is oxygen rich and sample 3 is oxygen deficient. This is confirmed by the XRD data. 


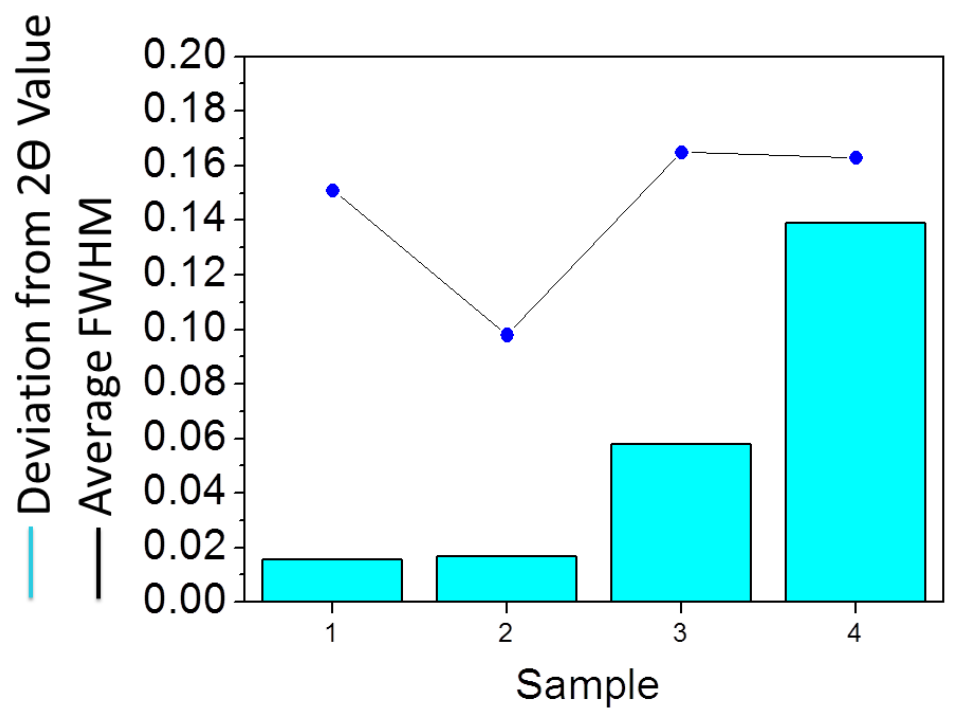

Fig. 5. The graph represents the average deviation of each sample from the JCPDS standard $2 \theta$ values and the average FWHM of all standard peaks of $\mathrm{ZnO}$ in the powder form.

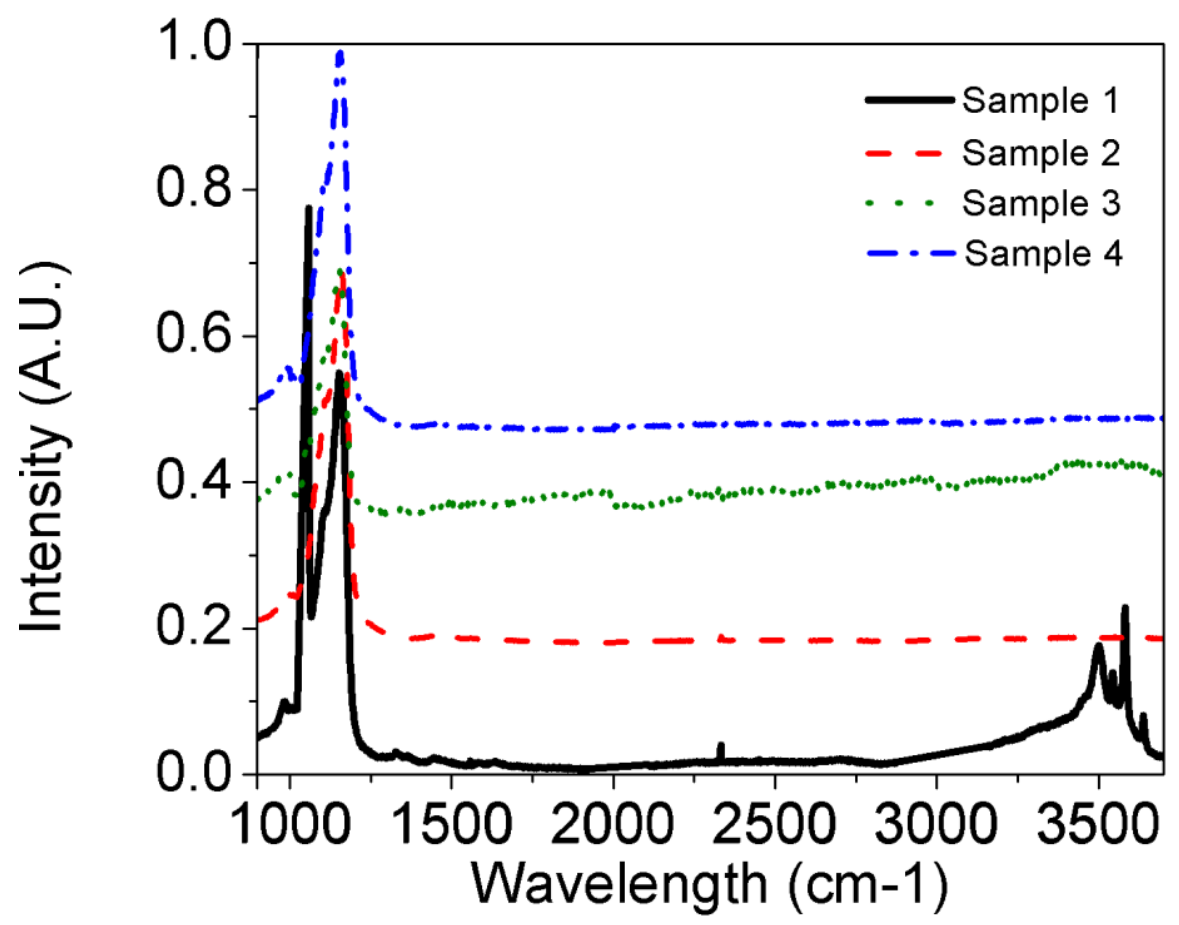

Fig. 6. Raman spectra of all $\mathrm{ZnO}$ samples taken using the $514 \mathrm{~nm}$ beam of an argon ion laser. Sample 1 clearly shows a peak around $1057 \mathrm{~cm}^{-1}$ and several hydrogen related peaks around $3500 \mathrm{~cm}^{-1}$. The Raman signal for sample 3 was weaker compared to the other samples and therefore has a larger background. The reason is believed to be due to the poor crystal quality of sample 3, creating less phonon-photon interactions. 
All samples showed a second harmonic property. A comparison of their PL emission shows that unannealed samples exhibit a higher bandedge emission relative to the broadband defect level emission in the visible wavelength. Annealing results in an increase of the defect related emission, Fig. 7. However, the second harmonic intensity and range increased after annealing for all samples, see Figs. 8 and 9. Samples 1, 2 and 4 had a strong second harmonic that was clearly visible to the human eye, even at average laser powers less than $10 \mathrm{~mW}$. For $\mathrm{ZnO}$ nanocrystals, SHG is an internal structural property that has to do with the birefringent noncentrosymmetric crystal structure and phase matching ability of the crystal. To determine the cause of the increase in SHG, we correlated the SHG efficiency with the XRD data.

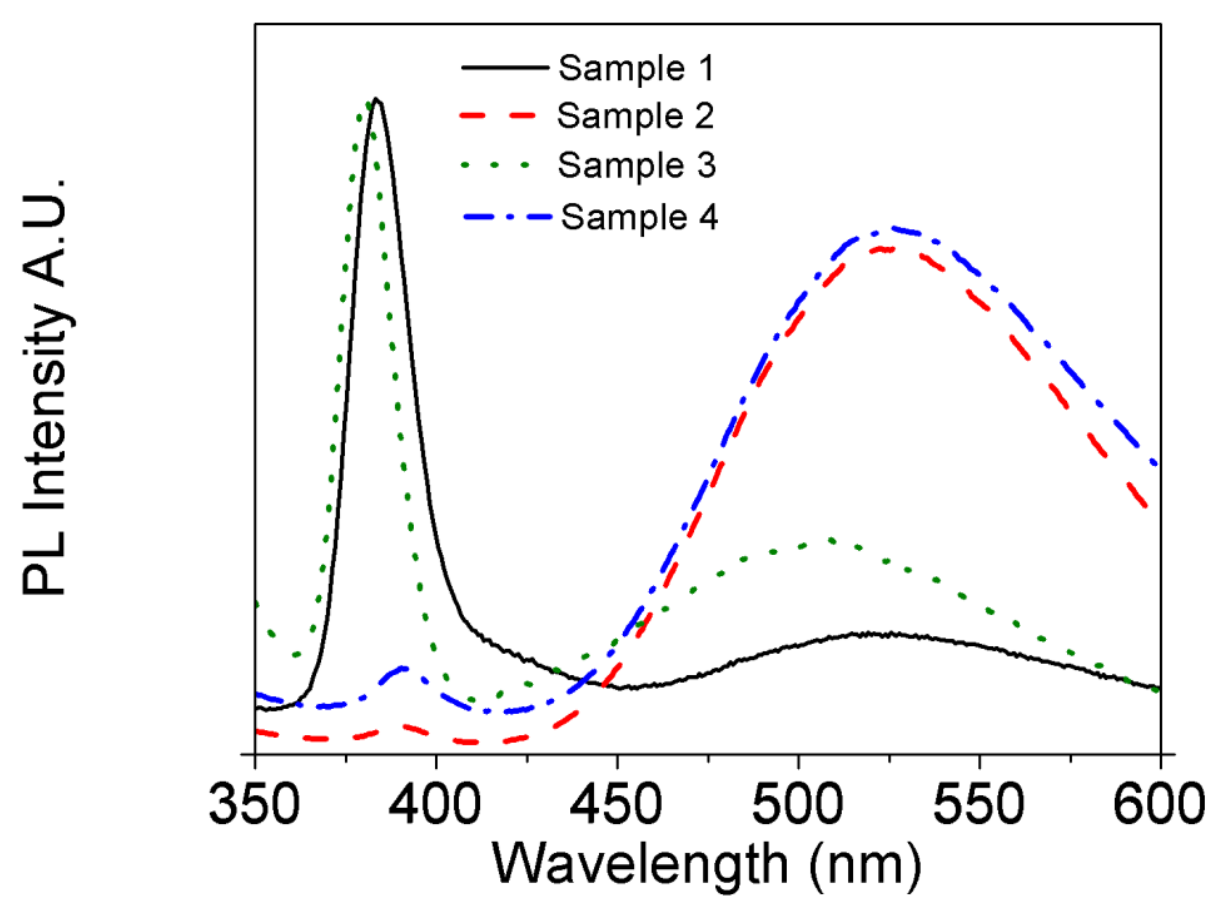

Fig. 7. Single photon photoluminescence from $\mathrm{ZnO}$ nanoparticles showing bandedge and surface defects relate emission from each sample due to the change in absorption efficiency of photons above the bandedge. 


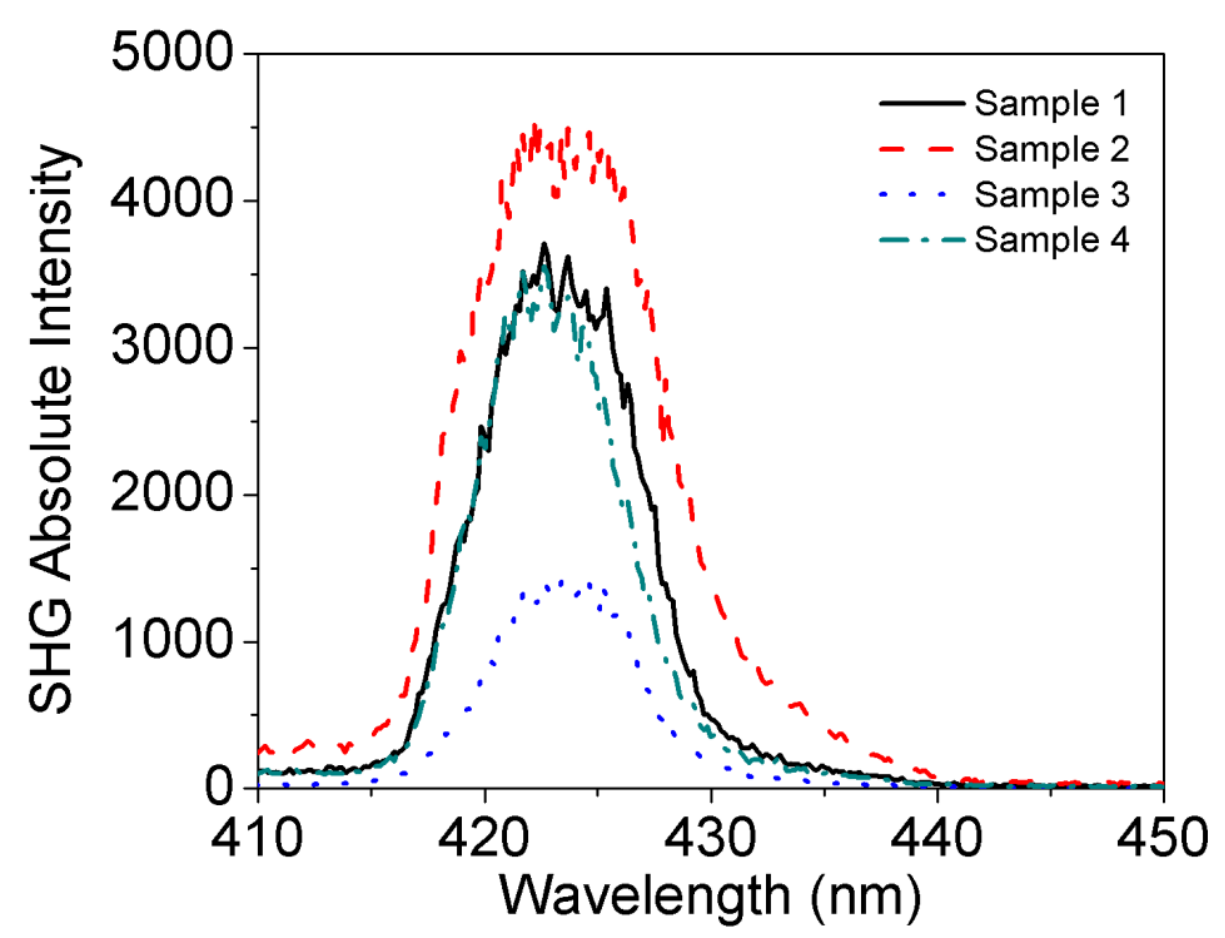

Fig. 8. A comparison of all the four samples at a power of $500 \mathrm{~mW}$ with identical focusing conditions at the fundamental wavelength $\sim 850 \mathrm{~nm}$. It demonstrates the increase in SHG after annealing.

According to XRD FWHM calculations, removing the hydrogen impurities in sample 1 by annealing increased the crystal quality, giving a more efficient second harmonic, see Fig. 8 [20-22]. The increase in the SHG is not believed to completely be due to the increased size of the crystals because the packing fraction for smaller crystals is higher compared to that of larger crystals. Comparing the ratios of the XRD peaks and the $2 \Theta$ measurement to the JCPDS standard also suggests sample 2 has a higher crystal quality compared to all other samples. Annealing sample 3 did not necessarily increase the quality of the sample according to FWHM calculations. Certain crystal orientations were improved by the annealing process, but others were actually degraded. It was also found that the peaks for sample 4 deviated further from the JCPDS standard than all other samples suggesting higher stress on the crystal structure, see Fig. 5. 


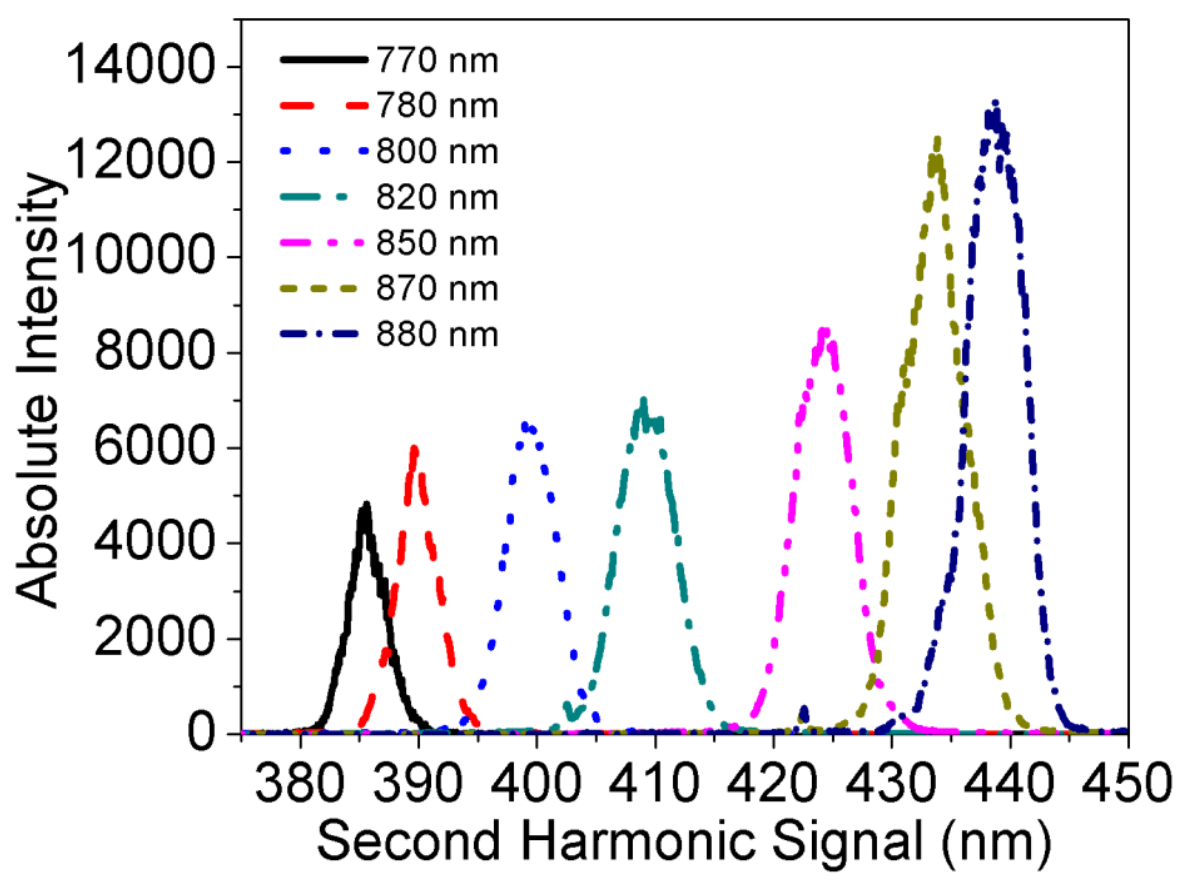

Fig. 9. Tunable range of SHG emission for various fundamental wavelengths from sample 2 at $500 \mathrm{~mW}$. The quadratic SHG power dependence on the input intensity was also confirmed.

Two photon TRPL measurements show a dominant $420 \mathrm{~nm}$ peak for sample 4 indicating a high number of internal $\mathrm{Zn}_{\mathrm{i}}$, see Fig. 10 [12]. Therefore, the increase in SHG is due to an increase of crystalline structure along certain orientations, but not crystal quality since a high number of $\mathrm{Zn}_{\mathrm{i}}$ were also created, causing degradation along other orientations. For samples 1 and 2, SHG was visible starting from fundamental wavelengths ranging from $755 \mathrm{~nm}$ to about $980 \mathrm{~nm}$. However, after $980 \mathrm{~nm}$ the laser power became too weak to detect the second harmonic. Part of the range of the second harmonic signal is shown in Fig. 9. The SHG efficiency was measured after considering the gratings, filter and laser power at the various wavelength, see Table 1.

It was observed that the SHG output increased slightly at the higher IR wavelengths of the laser, Fig. 9. However as the fundamental laser power was too weak to induce SHG beyond $980 \mathrm{~nm}$, the full range of the SHG process that can be realized from these $\mathrm{ZnO}$ samples is yet to be ascertained. The minimum SHG signal was observed to be more than $0.10 \mathrm{~mW}$ for an incident fundamental incident beam of $500 \mathrm{~mW}$ at $820 \mathrm{~nm}$. 
Table 1. Summary of the Effect of Hydrogen Content and Defects on the SHG, Single Photon and TPE Processes

\begin{tabular}{|c|c|c|c|c|}
\hline & Sample 1 & Sample 2 & Sample 3 & Sample 4 \\
\hline Conditions & $\begin{array}{ll} & \text { Atmospheric } \\
\text { Pressure } \\
\text { - } \\
\text { Arc Current of } \\
90 \mathrm{~A}\end{array}$ & $\begin{array}{l}\text { - Atmospheric } \\
\text { Pressure } \\
\text { Arc Current of } \\
90 \mathrm{~A} \\
\text { Annealed at } \\
1000^{\circ} \mathrm{C} \text { in } \\
\text { atmosphere }\end{array}$ & $\begin{array}{ll}- & 305 \text { Torr } \\
\text { Arc } \\
\text { Current of } \\
90 \mathrm{~A}\end{array}$ & $\begin{array}{ll}\text { - } & 305 \text { Torr } \\
\text { - } & \text { Current of } \\
& 90 \mathrm{~A} \\
\text { - } & \text { Annealed at } \\
1000^{\circ} \mathrm{C} \text { in } \\
\text { atmosphere }\end{array}$ \\
\hline $\begin{array}{l}\text { Single } \\
\text { Photon } \\
\text { Excitation }\end{array}$ & $\begin{array}{l}\text { Intense UV peak due to a } \\
\text { lower number of surface } \\
\text { defects }\end{array}$ & $\begin{array}{l}\text { Broad and intense visible } \\
\text { emission due to a high } \\
\text { number of surface defects }\end{array}$ & $\begin{array}{l}\text { Intense UV peak with } \\
\text { low green emission } \\
\text { due to a low number } \\
\text { of surface defects }\end{array}$ & $\begin{array}{l}\text { Broad and intense } \\
\text { visible emission due to } \\
\text { a high number of } \\
\text { surface defects }\end{array}$ \\
\hline $\begin{array}{l}\text { Two Photon } \\
\text { Excitation }\end{array}$ & $\begin{array}{l}\text { Comparatively the most } \\
\text { intense UV TPE signal } \\
\text { due to the high hydrogen } \\
\text { content and quality of the } \\
\text { crystal according to } \\
\text { Raman and XRD studies }\end{array}$ & $\begin{array}{l}\text { Higher crystal quality than } \\
\text { sample 1, but lower UV } \\
\text { TPE due to fewer DAP } \\
\text { after the release of } \\
\text { hydrogen according to } \\
\text { Raman and XRD studies }\end{array}$ & $\begin{array}{l}\text { Poor UV TPE due to } \\
\text { low crystal quality. } \\
\text { Low Raman signal } \\
\text { and XRD confirmed } \\
\text { these results }\end{array}$ & $\begin{array}{l}\text { Increased integrated } \\
\text { TPE compared to } \\
\text { sample } 3 \text { due to a high } \\
\text { number of } \mathrm{Zn}_{\mathrm{i}} \text { being } \\
\text { created by the } \\
\text { annealing process. } \\
\text { XRD shows an } \\
\text { increased crystal } \\
\text { quality along only } \\
\text { certain orientations }\end{array}$ \\
\hline $\begin{array}{l}\text { Second } \\
\text { Harmonic } \\
\text { Generation }\end{array}$ & $\begin{array}{l}\text { A high SHG was } \\
\text { observed due to the high } \\
\text { crystal quality. SHG is } \\
\text { dominant from } 750 \mathrm{~nm} \text { to } \\
\text { more than } 980 \mathrm{~nm}\end{array}$ & $\begin{array}{l}\text { Removing the hydrogen by } \\
\text { annealing created a higher } \\
\text { quality crystal, giving the } \\
\text { highest SHG signal } \\
\text { compared with all other } \\
\text { samples. SHG is dominant } \\
\text { from } 750 \mathrm{~nm} \text { to more than } \\
980 \mathrm{~nm}\end{array}$ & $\begin{array}{l}\text { A very weak SHG } \\
\text { was observed due to } \\
\text { poor crystal quality } \\
\text { of the sample. SHG } \\
\text { was dominant from } \\
810 \mathrm{~nm} \text { to } 960 \mathrm{~nm}\end{array}$ & $\begin{array}{l}\text { A high SHG was } \\
\text { observed due to the } \\
\text { increase } \\
\text { crystallization, but not } \\
\text { simply due to the } \\
\text { crystal quality. SHG } \\
\text { was dominant from } \\
770 \mathrm{~nm} \text { to more than } \\
980 \mathrm{~nm} \text {. }\end{array}$ \\
\hline Properties & $\begin{array}{ll}\text { - } & \text { High crystal } \\
\text { quality } \\
\text { - } \\
\text { Large } \\
\text { hydrogen } \\
\text { content } \\
\text { - } \text { High SHG } \\
\text { Comparatively } \\
\text { the most } \\
\text { efficient UV } \\
\text { TPE signal }\end{array}$ & 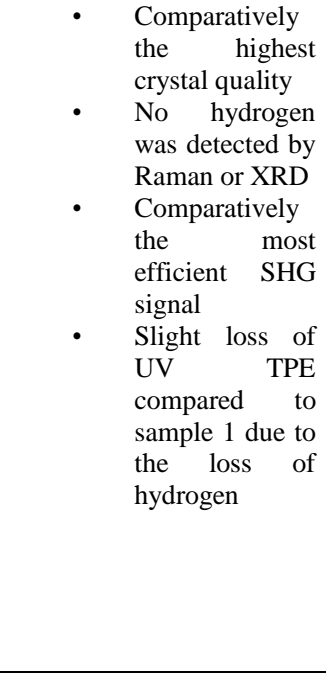 & $\begin{array}{ll}\text { - } & \text { Poor } \\
\text { crystal } \\
\text { quality } \\
\text { - } \\
\text { ho } \\
\text { hydrogen } \\
\text { detected } \\
\text { by Raman } \\
\text { or XRD } \\
\text { Weakest } \\
\text { SHG } \\
\text { signal of } \\
\text { all } \\
\text { samples } \\
\text { due to } \\
\text { poor } \\
\text { crystal } \\
\text { quality }\end{array}$ & $\begin{array}{ll}\text { - } & \text { Crystal } \\
\text { quality } \\
\text { improved } \\
\text { along } \\
\text { certain } \\
\text { orientations } \\
\text { compared } \\
\text { to sample 3 } \\
\text { High SHG } \\
\text { due to } \\
\text { improved } \\
\text { crystal } \\
\text { structure } \\
\text { along } \\
\text { certain } \\
\text { orientations } \\
\text { Red shifted } \\
\text { TPE due to } \\
\text { a high } \\
\text { number of } \\
\text { Zn } \\
\end{array}$ \\
\hline
\end{tabular}




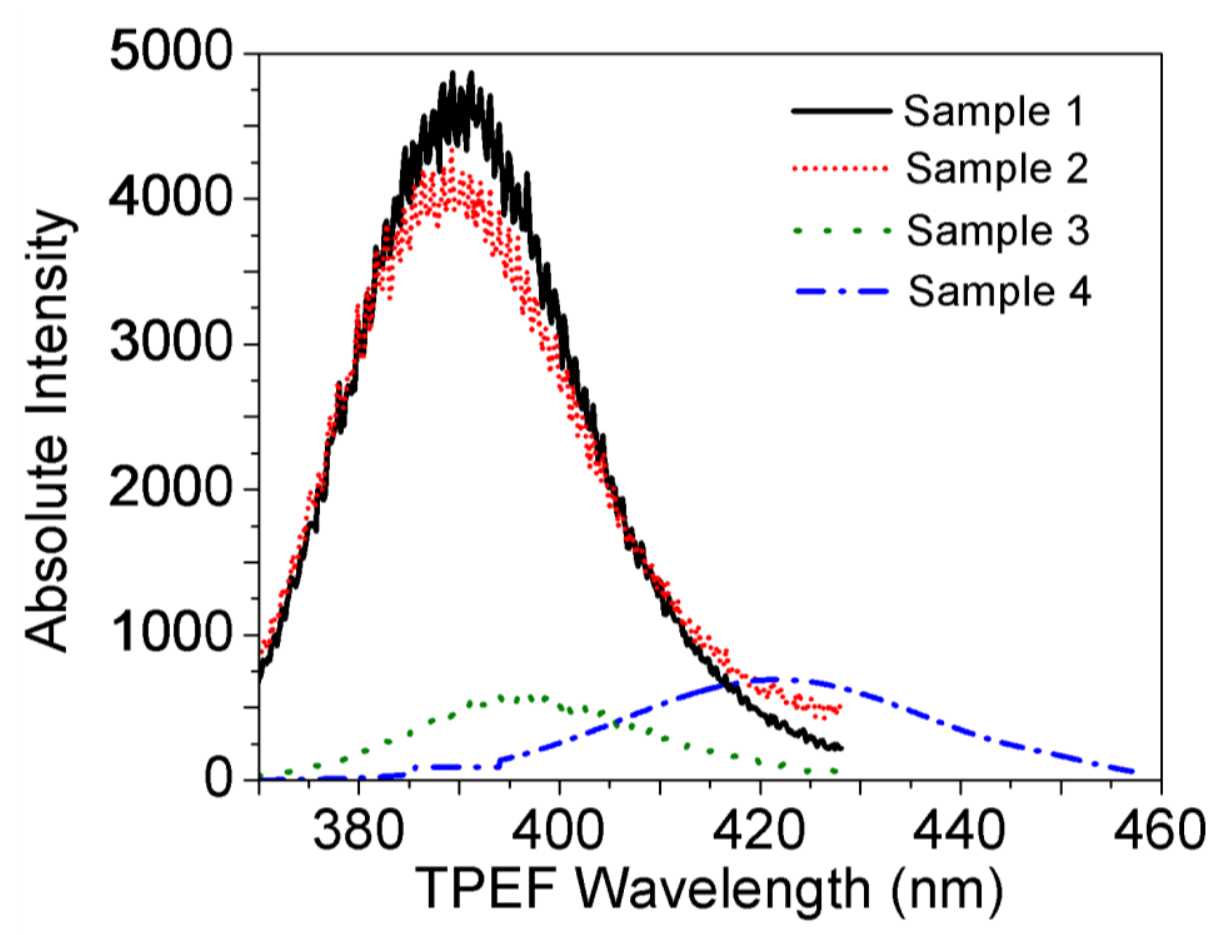

Fig. 10. TPEF spectra of all samples taken with the $736 \mathrm{~nm}$ beam of a pulsed laser at a power of $1.5 \mathrm{~W}$. The units are absolute with respect to each other.

It is also possible to induce a third order nonlinear process, $\left[\chi^{(3)}\right]$ in the $\mathrm{ZnO}$ nanocrystals due to two photon absorption, which results in two-photon excitation (TPE), Fig. 10 and Fig. 11(d). The TPE for these samples ranged from less than $710 \mathrm{~nm}$ to $755 \mathrm{~nm}$. All TPE spectra shown in Fig. 9 was obtained using femtosecond laser pulses at $736 \mathrm{~nm}$ wavelength with an average power of $1.5 \mathrm{~W}$ and showed almost no green emission despite the high concentration of defects at the surface of the annealed samples, see Fig. 7. Since the TPE is created internally, and the emission is mostly below the band edge needed for the deep level defect filled surface states to be excited, relatively little visible emission is observed.

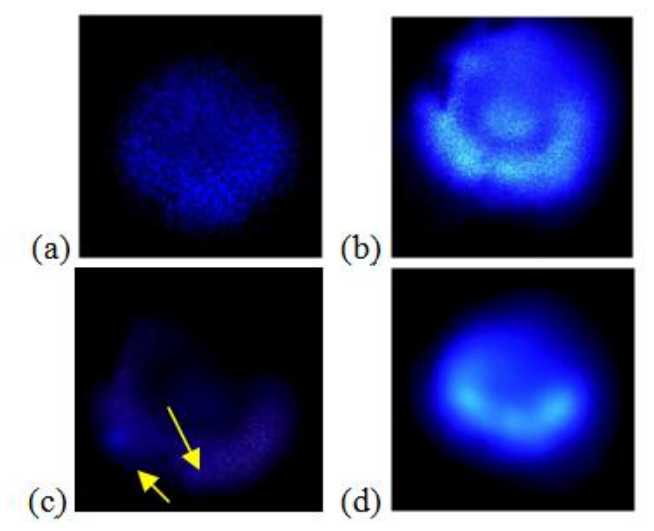

Fig. 11. (a) SHG as seen from a non-sensitive CCD camera, being generated by the $955 \mathrm{~nm}$ light. (b) SHG seen from the same CCD camera, generated using $800 \mathrm{~nm}$ pulsed laser. The signal is saturating the detector and shows the diffraction pattern of the incident beam. (c) Simultaneous SHG and TPEF at incident wavelength $755 \mathrm{~nm}$. The yellow arrows mark TPEF spots. (d) TPEF using the $750 \mathrm{~nm}$ beam of a pulsed laser. 
The higher energy TPE intensity of sample 1 is reduced after annealing, but the peak width does not drastically change. It is unlikely that the decrease is due to a higher number of non-radiative internal defects or radiative visible decay defects since the annealing process increased the internal crystal quality and visible emission was negligible for all samples in the TPE process.

The structure of the crystals changed after annealing, but only the single photon properties were drastically affected, Figs. 1, 2, 5, 8 and 10. Both annealed samples had similar, single photon PL spectra due to the same surface defects created during annealing. The high hydrogen content, which is known to increase the electron concentration, created more DAP emission in sample $1[4,13,14]$. The mechanism for the increase in TPE in sample 1 is therefore believed to be the increased electron concentration due to the high hydrogen content and a higher concentration of internal $\mathrm{V}_{\mathrm{Zn}}[15,16,21]$. The TPE from sample 4 is associated with a large and dominant number of internal $\mathrm{Zn}_{\mathrm{i}}[12]$.

\section{Conclusion}

We fabricated $\mathrm{ZnO}$ crystals that have controllable properties for biophotonic applications. The SHG and TPE processes of $\mathrm{ZnO}$ have been shown to be useful for biological applications. The crystals that we fabricated have strong emission and efficient SHG at wavelengths from less than $710 \mathrm{~nm}$ to more than $980 \mathrm{~nm}$. We have demonstrated it is possible to tune the nonlinear optical properties of $\mathrm{ZnO}$ using different fabrication conditions. TPE and SHG drastically increase to the point where both processes are easily visible with the human eye in nanocrystals. Heat from TPE can also be used to destroy cells. Because the wavelengths for nonlinear optical processes are tunable from visible to IR, it is ideal for in vivo studies. Furthermore, $\mathrm{SHG}$ from $\mathrm{ZnO}$ easily exceeds the limitations of current biological dyes and can be tuned to fit the biological window of the specimen.

\section{Acknowledgments}

The authors acknowledge the support from the National Science Foundation IRES program for the support of students. We would like to acknowledge the cooperation of Dr. Taisuke Hayashi of the Center for Integrated Research in Science at Shimane University for providing the FE-SEM facilities which was made possible through the Tatara Project, supported by the Ministry of Education, Culture, Sports, Science and Technology of Japan. 